\title{
Exploring end-member volcanism on the Moon at the Aristarchus Plateau
}

A White Paper submitted to the Planetary Science Decadal Survey 2023-2032

\author{
Primary Author \\ Erica R. Jawin \\ Smithsonian Institution National Museum of Natural History \\ jawine@si.edu \\ Co-Authors \\ Timothy Glotch, Stony Brook University \\ Ryan Watkins, PSI \\ Lauren Jozwiak, JHU APL \\ Sarah Valencia, University of Maryland College Park/NASA GSFC \\ Heather Meyer, JHU APL \\ R. Aileen Yingst, PSI \\ Brett Denevi, APL \\ Daniel Moriarty, NASA GSFC/USRA \\ Debra Needham, NASA Marshall \\ Sebastien Besse, European Space Astronomy Centre \\ Shashwat Shukla, Faculty ITC, University of Twente \\ Brad Jolliff, Washington University in St. Louis \\ Lisa Gaddis, USGS \\ Kristen Bennett, USGS \\ Jaclyn Clark, Arizona State University
}

Exploration of the Aristarchus region of the Moon would address many exploration goals and numerous SKGs articulated in previous studies. The Aristarchus plateau is an ideal place to explore for fundamental science, in situ resource utilization, and possibly an eventual site for a human outpost. The Aristarchus plateau region should be among the first non-polar targets for CLPS robotic landers and rovers, sample return, and human exploration. 


\section{Introduction}

Throughout its history, the surface of the Moon has been reshaped by countless episodes of volcanic activity. The vast majority of this activity can be characterized as effusive eruptions, peaking between 3-3.5 Ga ago, and forming the expansive lunar maria [1]. However, despite dominating the visual and volumetric record of volcanic lunar rocks, orbital remote sensing data and analyses of returned lunar samples have shown that these effusive flood basalt deposits are far from the only style of lunar volcanism. Some of the many variations of lunar volcanic morphologies include pyroclastic deposits formed from explosive volcanic eruptions; sinuous rilles carved by turbulent, erosive lava flows; unusual volcanic features called "irregular mare patches" (IMPs) that may represent the youngest lunar volcanic deposits; and numerous domes and exposures that in some cases formed from compositionally evolved, silicic melt compositions. These morphologies represent end-members on the spectrum of traditional volcanic eruption styles (e.g., pyroclastic deposits, sinuous rilles), ages (IMPs and young mare basalts), and compositions ( silicic deposits); however, they all provide a critical window into the characteristics, diversity, and evolution of the lunar interior through space and time.

The Aristarchus plateau (Figure 1), located on the lunar nearside in central Oceanus Procellarum, has one of the highest concentrations of volcanic features on the Moon and is commonly viewed as the Moon's most diverse volcanic region. This volcanic concentration may be tied to elevated concentrations of heat-producing elements in the region [2]. Critically, the Aristarchus plateau hosts or is immediately adjacent to the types of end-member volcanism described above, including the Moon's widest and deepest sinuous rille [3], the largest pyroclastic deposit, which is rich in iron-bearing volcanic glass [4], exposed silicic material that may indicate the presence of an excavated granitic or silicic volcanic complex [5, 6], very young mare basalts [1], and at least one IMP [7].

A sustained exploration strategy focused on lunar volcanism at the Aristarchus plateau would address many high-priority lunar science goals that inform our understanding of volcanism (Section 3). The plateau's location on the lunar nearside, as well as its large size and shallow slopes, enable easy access for future robotic and/or human exploration. The expansive pyroclastic deposit is well-suited for closing strategic knowledge gaps (SKGs) regarding operating on the lunar surface and is also enriched in useful resources including water and oxides, enabling in-situ resource utilization (ISRU). The Aristarchus plateau is therefore the ideal location on the Moon at which to explore the diversity of lunar volcanism in one accessible, traversable region.

\section{Diverse Volcanic Units on the Aristarchus Plateau}

Many open questions remain regarding lunar volcanism and the volatile content and composition of the lunar interior (Table 1); several of these could be addressed by exploration at the Aristarchus plateau. 
Table 1. Outstanding science questions to be addressed by exploring the Aristarchus Plateau

\begin{tabular}{|c|c|}
\hline Outstanding Science Questions & $\begin{array}{l}\text { Relevant Feature(s) on the } \\
\text { Aristarchus Plateau }\end{array}$ \\
\hline $\begin{array}{l}\text { 1. What is the genetic relationship (if any) between } \\
\text { pyroclastic deposits, sinuous rilles, and mare basalt flows? }\end{array}$ & $\begin{array}{l}\text { Pyroclastic deposits, sinuous } \\
\text { rilles, young volcanics }\end{array}$ \\
\hline $\begin{array}{l}\text { 2. Were explosive and effusive volcanic eruptions part of an } \\
\text { eruptive sequence, or were they distinct in time and origin? }\end{array}$ & $\begin{array}{l}\text { Pyroclastic deposit, sinuous } \\
\text { rilles }\end{array}$ \\
\hline $\begin{array}{l}\text { 3. What is the relationship between exposed silicic rocks and } \\
\text { the two other prominent styles of volcanism in the region } \\
\text { (explosive and effusive)? }\end{array}$ & $\begin{array}{l}\text { Silicic exposures, pyroclastic } \\
\text { deposit, sinuous rilles }\end{array}$ \\
\hline $\begin{array}{l}\text { 4. How variable was the volatile content of lunar magmas } \\
\text { and the lunar interior? }\end{array}$ & $\begin{array}{l}\text { Pyroclastic deposit, sinuous } \\
\text { rilles, silicic exposures, young } \\
\text { volcanics }\end{array}$ \\
\hline $\begin{array}{l}\text { 5. How did evolved magmas form on the Moon: silicate- } \\
\text { liquid immiscibility, basaltic underplating, or another } \\
\text { mechanism? }\end{array}$ & Silicic exposures \\
\hline $\begin{array}{l}\text { 6. Did the Aristarchus impact expose a silicic volcanic } \\
\text { (intrusive-extrusive) complex, and if so, how does its } \\
\text { mineralogy compare to other silicic constructs on the Moon? }\end{array}$ & $\begin{array}{l}\text { Silicic exposures, Aristarchus } \\
\text { crater }\end{array}$ \\
\hline
\end{tabular}

\subsection{Pyroclastic Deposit}

Lunar pyroclastic deposits are believed to have been sourced from great depths in the lunar mantle and have experienced less crystal fractionation than mare basalts [8]. Glass and devitrified beads from many of the larger pyroclastic deposits such as those at Aristarchus plateau are also enriched in iron and titanium oxides [e.g., 9]. In addition to a potential source for $\mathrm{Fe}$, Ti and $\mathrm{O}$ extraction, the pyroclastic glass and crystalline beads also have surficial vapordeposited coatings of volatile-element compounds (including $\mathrm{Au}, \mathrm{Ag}, \mathrm{Cu}, \mathrm{Cd}, \mathrm{F}, \mathrm{S}, \mathrm{Zn} \mathrm{[10])} \mathrm{that}$ provide a glimpse of the lunar interior composition and volatile component, and may prove to be valuable resources.

The primary pyroclastic deposit on the Aristarchus plateau is a key unit for scientific exploration owing to its distinct size, compositional properties, and apparent abundance of volatiles. This deposit is spatially expansive, the largest on the Moon $\left(\sim 50,000 \mathrm{~km}^{2}\right)$, and up to several tens of meters thick $[4,11]$. Compositional analyses using Lunar Prospector geochemical data suggest the plateau hosts materials with intermediate Ti content and high Th concentrations which may indicate that a KREEP component was incorporated into parental magmas [2]. Spectral analyses suggest that the pyroclastic deposit is rich in volcanic glass [e.g., 4] and contains evidence of indigenous water in concentrations up to several hundred ppm [12]. 

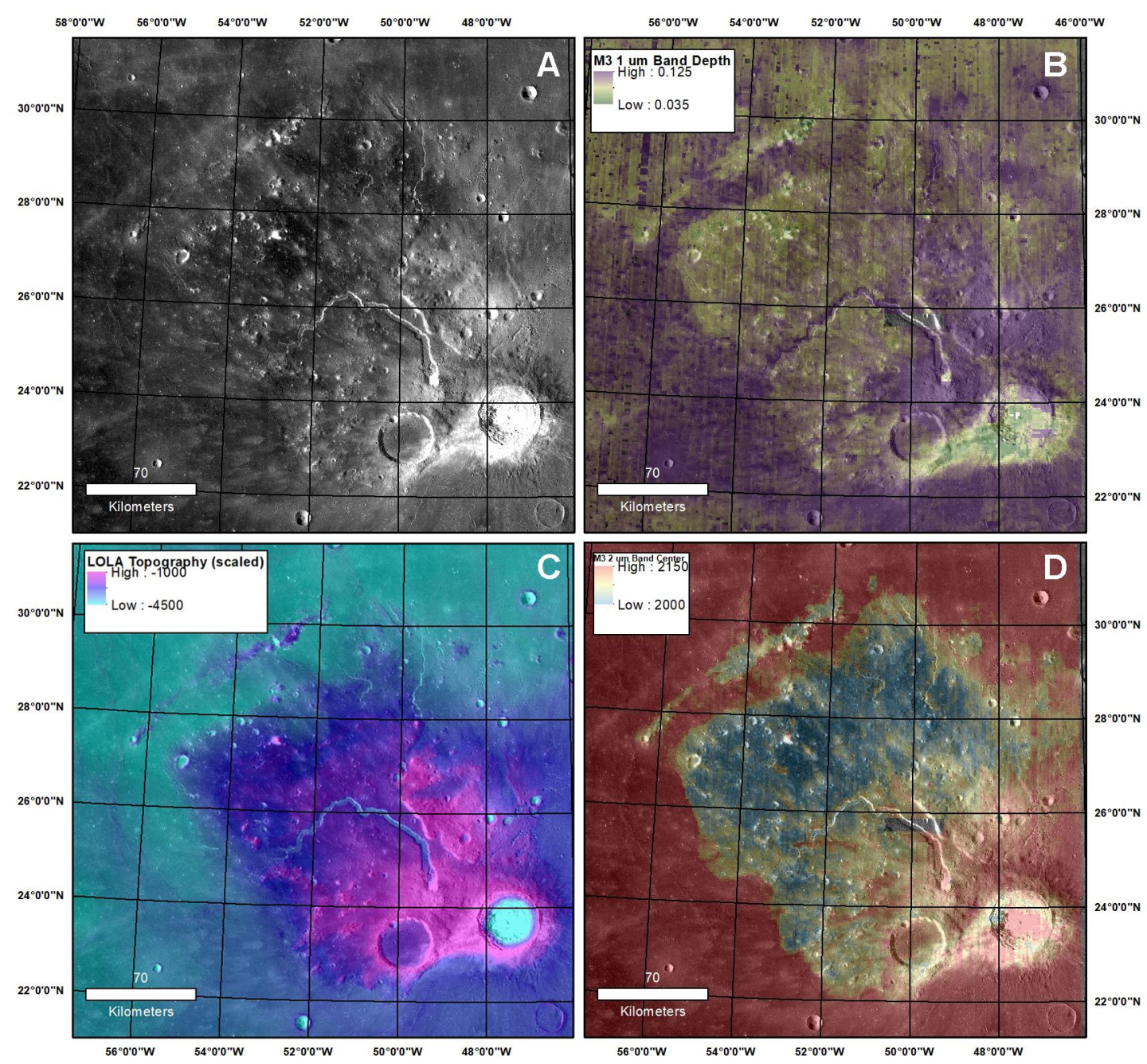

Fig. 1. The Aristarchus plateau. (A) LROC WAC mosaic. (B) Moon Mineralogy Mapper (M $\left.{ }^{3}\right) 1$ $\mu \mathrm{m}$ band depth. Deeper absorption bands (purple) are correlated with higher mineral abundances and/or fresher surfaces. (C) Lunar Orbiter Laser Altimeter topography. Topographically high regions are pink, low regions are cyan. (D) $\mathrm{M}^{3} 2 \mu \mathrm{m}$ band center. Blue colors indicate Mg-rich pyroxenes and/or quenched Fe-bearing glass; red colors show pyroxene with higher $\mathrm{Ca}$, Fe. Yellow/blue regions indicate the extent of the pyroclastic deposit compared to the red maria.

\subsection{Sinuous Rilles}

Sinuous rilles are understood to have formed via a combination of mechanical and thermal erosion caused by the rapid eruption of turbulently flowing lava [3]. These features are of scientific interest because they have eroded into the lunar surface, providing important constraints on the rheology of the surface and of the flowing lava. Rille channels can also expose crustal stratigraphy, which enables access for exploration.

The large sinuous rille Vallis Schröteri is the most distinctive geologic feature on the Aristarchus plateau and is the widest and deepest sinuous rille on the Moon. Initiating at a depression informally referred to as "Cobra Head", the rille is $\sim 4 \mathrm{~km}$ wide and $\sim 170 \mathrm{~km}$ long, 
with a secondary rille located inside Vallis Schröteri [3]. The presence of spatter cone-like features immediately adjacent to Cobra Head suggests that the pyroclastic deposit erupted from the same source as the lavas that formed the sinuous rille [13], representing a possible link between explosive and effusive eruptions on the plateau.

Radar data suggest that erupted lavas at least briefly overtopped Vallis Schröteri, mantling part of the plateau with mare basalts that were subsequently buried by pyroclastic deposits [14]. At the terminal margin of Vallis Schröteri, the nested rille cross-cuts the main channel and extends west off the plateau, terminating within younger mare basalt units of Oceanus Procellarum (the P60 unit, discussed below).

\subsection{Silicic Exposures}

Silicic materials on the Moon represent compositionally evolved magmas, in contrast to the dominantly basaltic lithologies of most other lunar volcanic deposits. Silicic lithologies are rare in the Apollo sample collection, and their petrogenesis is a subject of considerable debate. Correlations between $\mathrm{SiO}_{2}$, Th, and other incompatible trace elements, and $\mathrm{H}_{2} \mathrm{O}$ provide constraints on lunar interior composition and evolution. In addition, they can provide insight into the generation of felsic lithologies in a planetary context in the absence of plate tectonics.

The Copernican-aged Aristarchus crater ( 280 Ma, [15]) excavated plagioclase feldspar-rich crustal materials, pyroclastic glass, and olivine [6], as well as silicic materials that may represent intrusive volcanic materials [5] or an intrusive-extrusive complex (Figure 2). Silicic materials may also be exposed in Cobra Head, perhaps suggesting bimodal volcanism in the region, and by Väisälä crater, $50 \mathrm{~km}$ north of Aristarchus [16]. Mons Herodotus, a $6 \mathrm{~km}$-wide dome $\sim 170 \mathrm{~km}$ NW of Aristarchus crater also appears to be constructed from silicic volcanic rocks, suggesting a vast subsurface distribution of silicic materials in the region. Thus it appears that relatively rare, non-basaltic volcanism has occurred in this region.

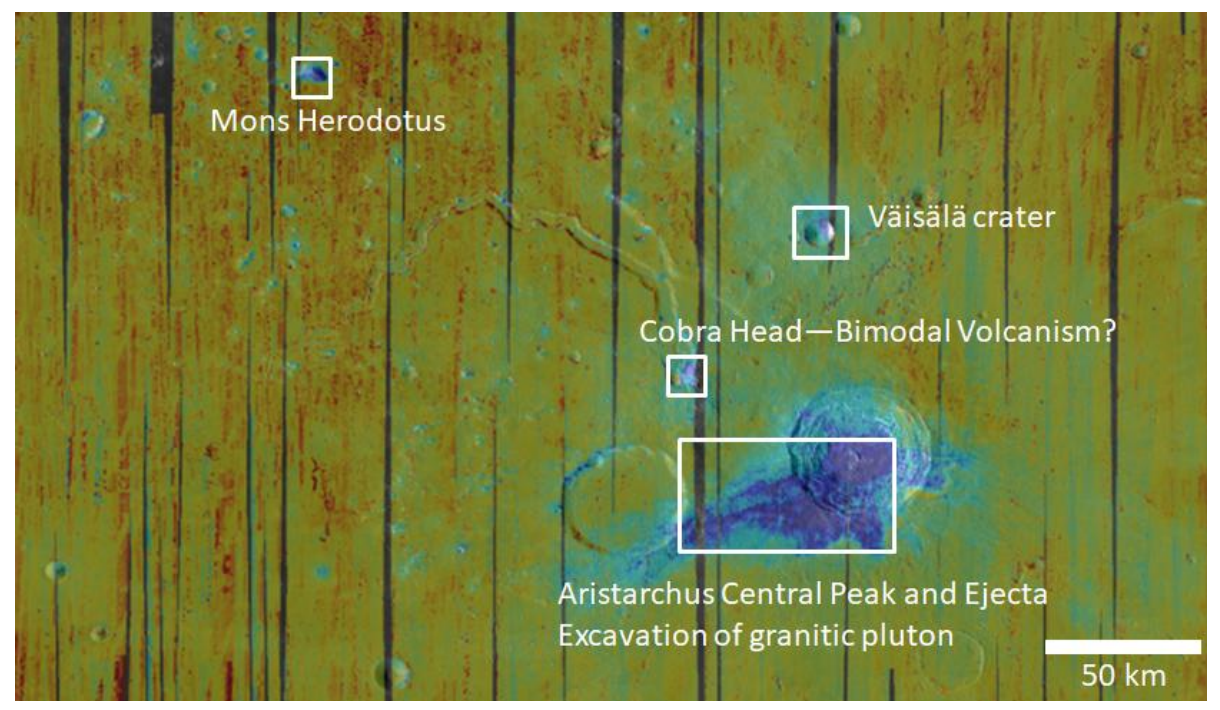

Figure 2. Diviner map of Christiansen Feature location, which is an indicator of composition. Cool colors represent the presence of silicic compositions. Note potential silicic exposures in Aristarchus crater ejecta and in Väisälä crater, within Cobra Head, and on Mons Herodotus. 


\subsection{Young Volcanics: P60 and IMPs}

The main period of mare basalt eruption occurred during the late Imbrian period, 3.8-3.6 $\mathrm{Ga}$; however, smaller eruptions continued well past this period, until as recently as $\sim 1$ Ga (Figure 3) $[1,17]$. The youngest mare basalts are of interest because they provide insight into the relationship between age, source depth, and source-region productivity within the Procellarum KREEP Terrane. The youngest of these studied mare units $(\sim 1 \mathrm{Ga})$ is referred to as the P60 unit, located adjacent to the Aristarchus plateau and embaying its west, south, and east portion (shown in red in Figure 3). The close spatial association of P60 to the Aristarchus plateau, and the observation that the nested sinuous rille inside Vallis Schröteri terminates in the P60 unit, suggests that Cobra Head could be an eruptive source of the young mare basalts. Several vents have been identified within the P60 unit that may instead represent sources of much of the mare basalts within P60 [17], so further exploration and analysis is required to determine the relationship between the volcanic units on the Aristarchus Plateau and those in P60. If there is a genetic relationship between Cobra Head and the P60 basalts, it would provide a link between sinuous rilles and their volcanic products (mare basalts), and potentially link effusive and explosive volcanic eruptions, if the eruption of the pyroclastic deposit is also linked to the formation of Vallis Schröteri (as discussed above).

Irregular mare patches are enigmatic features that appear to be volcanic in origin and may be extremely young, erupting as recently as $100 \mathrm{Ma}$ [7]. Characterizing these very late-stage eruptions could help to constrain the thermal evolution of the lunar interior. At least one IMP is observed at Aristarchus, located on the ejecta deposit of Aristarchus crater [7], which further emphasizes the volcanic diversity of the Aristarchus plateau.

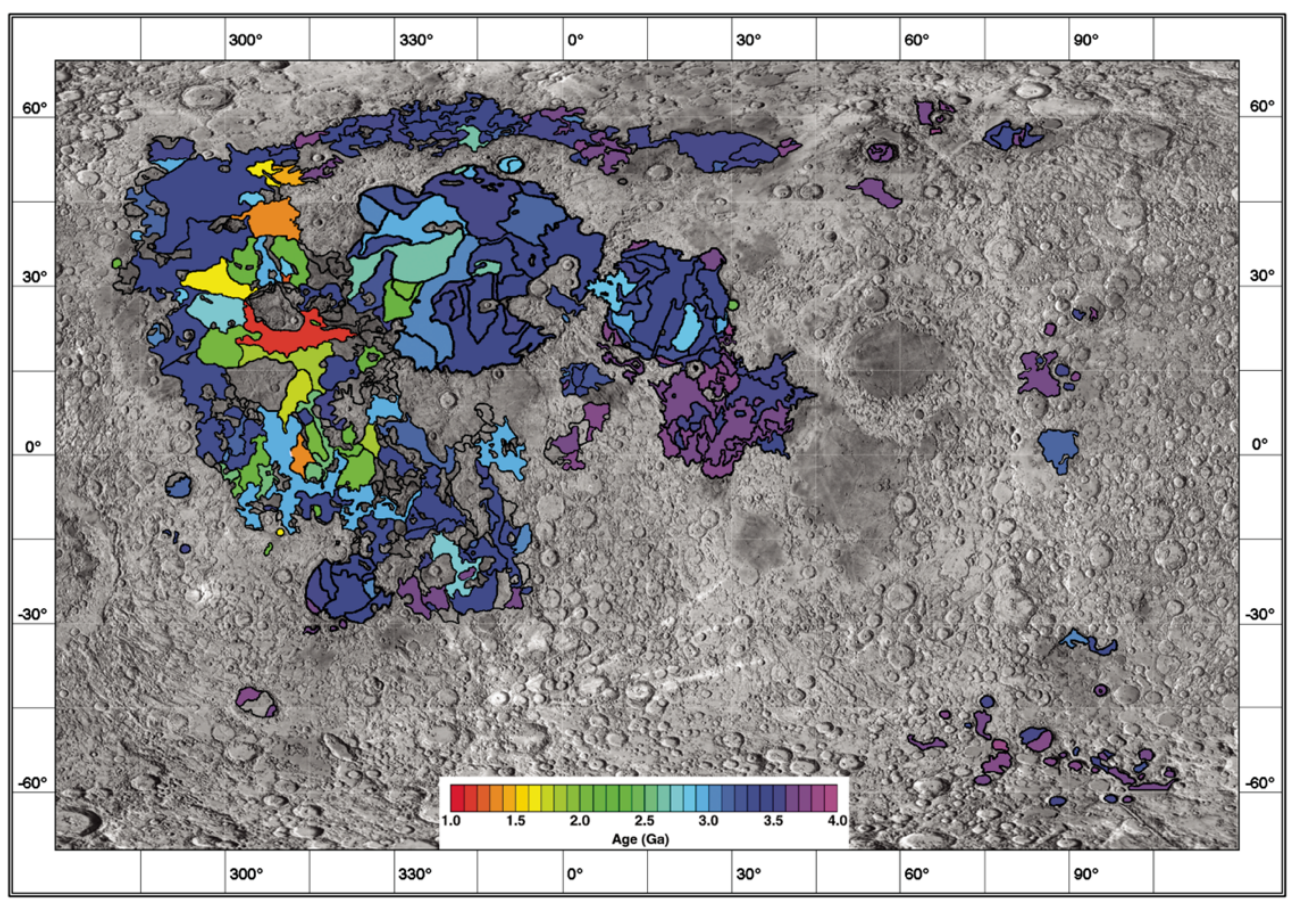

Figure 3. Spatial distribution of model ages for mare units (from [1], their Figure 17). P60 is the youngest unit, highlighted in red just south of the Aristarchus plateau. 


\section{Relevance to Science Priorities}

Exploring the Aristarchus plateau would directly address several major lunar science priorities, as outlined in documents including the 2007 National Research Council report, Scientific Context for the Exploration of the Moon (referred to as the SCEM report, [18]) and the 2017 Lunar Exploration Analysis Group (LEAG) Specific Action Team Report Advancing Science of the Moon (ASM-SAT) [19]. Scientific goals outlined in these reports that could be addressed at the Aristarchus plateau are listed below.

Exploring the diverse and abundant volcanic features at the Aristarchus plateau would directly address SCEM Goal 5. Geochemical data from the plateau's volcanic and crustal deposits can help to constrain the conditions and variability of the lunar interior, thereby addressing SCEM Goal 2. The Aristarchus plateau contains a diversity of geologic units on the plateau and exposed in Aristarchus crater ejecta; understanding the composition of these geologic units would address SCEM Goal 3. Aristarchus crater is a well-preserved Copernicanaged impact crater that exposed diverse lithologies, providing the opportunity addressing SCEM Goal 1 and SCEM Goal 6. The pyroclastic deposit is enriched in hydrated materials that allow for the lunar volatile budget to be quantified and characterized, which would address the ASMSAT Goal The Lunar Water Cycle.

\section{Open Strategic Knowledge Gaps (SKGs) addressed at the Aristarchus Plateau}

Several open SKGs could be addressed by exploring the Aristarchus plateau. SKGs were defined by two LEAG Specific Action Teams, in conjunction with NASA's Human Spaceflight Architecture Team (https://www.nasa.gov/exploration/library/skg.html). Three broad SKG themes were defined, all of which could be addressed by landing and/or roving on the Aristarchus plateau [20]:

1. Understand the lunar resource potential. The resource potential at Aristarchus is high because the pyroclastic deposit is large and appears to be enriched in Fe- and O-rich volcanic glasses (coated in vapor-deposited rare elements) and potentially indigenous water [12], thus enabling identification and quantification of $\mathrm{O}, \mathrm{Fe}, \mathrm{H}$, and other volatile species. In addition, sampling techniques that preserve volatiles could be developed and tested.

2. Understand the lunar environment and its effects on human life. The radiation environment on the lunar surface could be characterized and radiation shielding techniques, such as construction with fine-grained pyroclastic deposits, could be assessed for their feasibility.

3. Understand how to work and live on the lunar surface. The generally low slopes on the plateau present a unique region in which to assess traversability within the thick pyroclastic deposit, including testing excavating, transporting, and roving technologies.

\section{Exploring the Aristarchus Plateau}

Several characteristics of the Aristarchus plateau make it an ideal location to explore and a high priority for sample return [e.g., 20, 21]. The plateau is located on the lunar nearside, providing relative ease of access and constant line-of-sight for communication. The relatively 
low slopes and fine-grained pyroclastic deposit present on much of the plateau provide an array of potential landing sites with access to geologically interesting locations. The diverse units exposed in the region could enable the assessment of multiple science priorities within a spatially limited region, providing high bang-for-buck science. The apparent concentrations of potentially utilizable resources including metals (e.g., Fe, Ti), O, and water in the pyroclastic deposit could be used for critical functions including life support, habitat construction, radiation shielding, and propellant.

Recommendation: The Aristarchus Plateau should be an exploration target for landed missions in the next decade, including among the first non-polar targets for CLPS robotic landers and rovers, sample return, and human exploration.

\section{References}

[1] Hiesinger, H. et al., (2011), GSA Special Paper 477, 1-51.

[2] Hagerty, J. J. et al. (2009), JGR, 114, E4.

[3] Hurwitz, D. M. et al. (2013), PSS, 79-80, 1-38.

[4] Gaddis, L. R. et al. (2003), Icarus, 161, 2, 262-280.

[5] Glotch, T. D. et al. (2010), Science 329, 1510-1513.

[6] Mustard, J. F. et al. (2011), JGR, 116(E6), E00G12.

[7] Braden, S. E. et al. (2014), Nat. Geo., 7, 787-791.

[8] Shearer, C. K. \& Papike, J. J. (1993), GCA, 57, 19, 4785-4812.

[9] Hawke, B. R., et al. (1990), 20 $0^{\text {th }}$ LPSC, 249-258.

[10] McCubbin, F. M., et al. (2015), Am Min, 100, 1668-1707.

[11] McEwen, A. S. et al. (1994), Science, 266, 1858-1862.

[12] Milliken, R. E. and Li, S. (2017), Nat, Geo., 10, 561-565.

[13] Head, J. W. and Wilson, L., (2017), Icarus, 283, 176-223.

[14] Campbell, B. A. et al. (2008), Geology, 36, 2, 135-138.

[15] Zanetti, M. et al. (2017a), Icarus, 298, 64-77.

[16] Zanetti, M. et al. (2017b), $48^{\text {th }}$ LPSC, Abstract \#2320.

[17] Stadermann, A. C. et al. (2018), Icarus, 309, 45-60.

[18] National Research Council (2007), The scientific context for exploration of the Moon.

[19] Lunar Exploration Analysis Group (2017). Advancing science of the Moon: Report of the specific action team. Houston, Texas, United States of America.

[20] Jawin, E. R. et al. (2019), Earth and Space Science, 6, 2-40.

[21] Valencia, S. N. (2020), High Priority Sites for Returned Lunar Samples. White Paper submitted to the Decadal Survey. 